\title{
The Positive Association between Proton Pump Inhibitors and Clostridium Difficile Infection
}

Dania Tawam, PharmD Candidate; Michael Baladi, PharmD Candidate; Paiboon Jungsuwadee, PhD; Grace Earl, PharmD; Jayoung Han, PhD

Fairleigh Dickinson University School of Pharmacy and Health Sciences

\begin{abstract}
Background: Proton pump inhibitors (PPIs) are among the most commonly used medications by patients due to its availability over the counter and frequent prescribing by physicians to treat and alleviate symptoms of gastroesophageal reflux disease. Recently, the FDA issued a warning with respect to the utilization of PPIs and risk of developing Clostridium difficile infections (CDI). The most commonly known medications to cause CDI are antibiotics. However, available studies suggest an association and increase in risk for CDI with PPI use as well.

Objective: The purpose of this research is to review and summarize data currently available on the association between PPIs and CDI. Methods: To search for eligible studies, EBSCO engines were investigated using proton pump inhibitors or PPIs and Clostridium difficile or C. diff. as search terms. Meta analyses and systematic reviews published between 2000 and 2020 on adult patients were considered. Results: Eight meta-analyses and systematic reviews met the inclusion criteria. They included studies conducted in the US, Europe, Asia and Canada on inpatient and outpatient adults. The final result for all 8 studies showed a statistically significant association between $P P I s$ and $C D I$ ranging from mild to high risk.
\end{abstract}

Conclusion: Currently available data suggest a positive association between PPIs and CDI.

Keywords: Clostridium difficile infection, proton pump inhibitors, review

\section{Introduction}

In 2017, the United States Food and Drug Administration (FDA) issued a warning regarding the use of PPIs and risk of developing Clostidium difficile infection (CDI). The claim stems from reports and studies the FDA reviewed where healthcare professionals or patients who were on proton pump inhibitors (PPIs) filed reports of CDI incidences to the FDA's Adverse Event Reporting System (FAERS). These reports involved the elderly, patients with chronic conditions or patients on broad spectrum antibiotics. They also viewed observational studies and metaanalysis that confirmed the association. ${ }^{1}$

Antibiotics have been identified as the most common cause of $\mathrm{CDI}$, due to their significant alteration of the gut microbiome. ${ }^{2}$ In particular, oral antibiotics such as penicillins, clindamycin, cephalosporins, and fluoroquinolones are the main culprits. ${ }^{2,3}$ However, antibiotics are not solely responsible for CDI. Use of PPIs, a frequently prescribed class of medications, have been linked to CDI as well. They have proven to be an effective therapeutic option in a variety of gastric acid-related disorders including gastroesophageal reflux disease (GERD), peptic ulcer disease, Helicobacter pylori eradication therapy, dyspepsia and stress ulcer prophylaxis. The incidence of PPI use varies depending on the healthcare setting. The number of PPI prescriptions filled by outpatient physicians has remained

Corresponding author: Jayoung Han, PhD

Assistant Professor, Pharmacy Practice

Fairleigh Dickinson University

School of Pharmacy and Health Sciences

230 Park Avenue, Florham Park, NJ 07932, USA

Phone: 973-443-8419; Email: jayoung@fdu.edu constant. In contrast, PPI orders have increased in the hospital setting. ${ }^{4}$ Previous studies showed that once PPIs were started in the hospital, more than $50 \%$ of patients continued to take them 3 to 6 months after discharge, even in the absence of an indication, possibly out of fear that their symptoms would reoccur after discontinuation. ${ }^{5}$ Therefore, not only is PPI use increasing in the inpatient setting, many patients are also continuing their PPI regimen after discharge, adding to the ever increasing prevalence of PPI use. Due to the correlation between PPIs and CDIs, the overuse of PPIs is alarming because their use contributes to the ever increasing incidence of CDI.

As of 2020, there are six PPIs approved by the FDA, namely omeprazole, esomeprazole, lansoprazole, dexlansoprazole, pantoprazole and rabeprazole. ${ }^{6}$ There are slight differences among these agents relating to their pharmacokinetic properties, metabolism, and FDA approved clinical indications. Regardless, they all have the same mechanism of action. They inhibit the $\mathrm{H}^{+} / \mathrm{K}^{+}$ATPase pump in gastric parietal cells, thus decreasing acid secretion by inducing profound hypochlorhydria. A single oral PPI dose will raise gastric $\mathrm{pH}$ in most patients from 2.0 to over $6.0 .^{7}$ On average, PPIs-reliably maintain intragastric $\mathrm{pH}>4$ for 15 to 21 hours after single daily use. $^{8}$ The purpose of this paper is to summarize the evidence on PPI use from meta-analysis and systematic review studies to characterize the risk associated with CDI.

\section{Epidemiology}

CDIs are a well-known and widespread phenomenon in healthcare. In 2011, there were an estimated 453,000 cases of CDI in the United States, at 148 cases per 100,000 persons, and an estimated 29,300 associated deaths. ${ }^{9}$ In 2017, a total of 15,512 cases of CDI were reported to the Centers for Disease 
Control and Preventions (CDC) Emerging Infection Program in 35 counties in 10 US states (California, Colorado, Connecticut, Georgia, Maryland, Minnesota, New Mexico, New York, Oregon, and Tennessee). The incidence was highest among those aged $\geq 65$ years, females, and whites. ${ }^{10}$ Over the 20122016 period, CDIs incurred a mean cost of $\$ 10,528$ per person for inpatient treatment and average length of hospital stay of 5.9 days. $^{11}$

\section{Pathogenesis and pathophysiology of CDI}

Clostridium difficile is an anaerobic, gram-positive, sporeforming bacterium that is spread via the fecal-oral route and subsequently germinates within the gastrointestinal tract, producing vegetative cells capable of generating toxins. ${ }^{12,13}$ The main toxins contributing to the pathogenicity of $C$. difficile are toxin $A(T c d A)$ and toxin $B(T c d B)$, which have enterotoxic and cytotoxic activity, respectively. ${ }^{14}$ These toxins can cause symptoms and disease that range from symptomatic diarrhea to pseudomembranous colitis, toxic megacolon, sepsis with organ failure and even death. ${ }^{15}$ On the contrary, $C$. difficile can colonize a human's colon without causing any symptoms of infection (asymptomatic $C$. difficile colonization). For this reason, Infectious Diseases Society of America (IDSA) recommends that only symptomatic patients be tested for CDI. ${ }^{16}$

In order to cause symptoms, $\boldsymbol{C}$. difficile spores must germinate to produce vegetative cells. Substantial amount of $C$. difficile spores must pass through the acidic environment of the stomach and germinate upon exposure to bile in the neutral environment of the colon. ${ }^{17} \mathrm{~A}$ study found that primary bile acid (taurocholic and glycocholic acids) act as cogerminants to $C$. difficile. It also found that deoxycholate, a metabolite of cholate produced by the normal intestinal flora, induces germination of $C$. difficile spores but prevents the growth of vegetative $C$. difficile. ${ }^{18}$ A patient with disturbed colonic flora will lack deoxycholate but will have more cholate available for use by the bacterium, allowing for increased growth, thereby placing the patient at an increased risk for developing CDI. ${ }^{18}$

Following expression and release from the bacterium, Toxins $A$ and $B$ are endocytosed by colonic epithelial cells into the cytosol, inactivating small GTP-binding proteins, which include Rho, Rac, and $\mathrm{Cdc} 42$. These proteins have a distinct role in cellular signaling pathways and are necessary for regulating cell function, specifically for cytoskeletal organization. Inactivation of these substrates occurs through monoglucosylation of a single reactive threonine, which lies within the effector-binding loop and coordinates a divalent cation critical to binding GTP. By glucosylating small GTPases, actin in the cytoskeleton condenses and the cell starts to round, causing damages to the cytoskeleton and ultimately colonic epithelial cell death. ${ }^{19}$

In addition to regulating actin cytoskeleton, Rho controls the formation of perijunctional rings at the apical side of epithelial cells. ${ }^{20}$ Inactivation of Rho and subsequent loss of perijunctional rings and focal adhesions lead to increased permeability of the epithelial layer of the intestines. ${ }^{21}$ Chamber studies using isolated mucosal strips from guinea pig ileum demonstrated that toxin $\mathrm{A}$ decreases electrogenic $\mathrm{Na}^{+}$absorption while eliciting a $\mathrm{Cl}^{-}$secretory response. ${ }^{22}$ In addition to the above, the C. difficile toxins initiate an inflammatory cascade that causes increased damage to host tissues resulting in fluid exudation, diarrhea symptoms, and contributes to development of pseudomembranous colitis. ${ }^{23}$

\section{Potential mechanism for PPI-associated CDI}

It has been widely accepted that $\mathrm{pH}$ is an important parameter that impacts $C$. difficile growth. The role of PPIs associated with CDI remain to be elucidated. Nonetheless, a study done in 2016 examined the effect of alkaline stool and risk of CDI. This study included 228 patients with signs and symptoms of CDI, of whom $86.7 \%$ both tested positive for CDI and had alkaline stool. ${ }^{24}$

Another study published in 2020 investigated the impact of $\mathrm{pH}$ on growth, sporulation, motility, and toxin production in $C$. difficile strains 630 $\Delta e r m$ and R20291 in-vitro. Both $C$. difficile strains are hypervirulent; $630 \Delta e r m$ is a derivative of a past epidemic strain and is erythromycin sensitive. ${ }^{25}$ R20291 is a strain that was isolated from an outbreak in the UK in $2006 .^{25,26}$ The study results indicated that sporulation frequency was the lowest under acidic $\mathrm{pH}$, while alkaline colonic $\mathrm{pH}$ increased $C$. difficile growth for both strains. ${ }^{27}$

Together, these may explain the high prevalence of CDIs in patients with alkaline stools, as $C$. difficile spores are unable to sporulate with low gastric $\mathrm{pH}$ whereas high gastric $\mathrm{pH}$ and alkaline $\mathrm{pH}$ of the intestine facilitates $\mathrm{C}$. difficile survival allows for the sporulation and germination of vegetative form of the bacterium. This evidence suggests that acid suppressive therapies, such as PPIs, facilitate vegetative $C$. difficile survival and growth, increasing the likelihood of acquiring CDI.

\section{Diagnostic testing}

IDSA recommends that patients with unexplained and new onset $\geq 3$ unformed (watery and non-bloody) stools in 24 hours be tested for $\mathrm{CDI} .{ }^{16}$ Various laboratory tests are available to detect $C$. difficile in stool specimens. These tests include nucleic acid amplification test (NAAT), enzyme immunoassay (EIA) for C. difficile glutamate dehydrogenase (GDH), EIA for $C$. difficile toxins $A$ and $B$, cell culture cytotoxicity assay, and selective anaerobic culture. NAAT usually targets the toxin $B$ gene, $t c d B$, and has high sensitivity and specificity in symptomatic patients. It also provides rapid results, but it has a high rate of false positives in asymptomatic colonized patients. ${ }^{28}$ EIA for toxins $A$ and $B$ provide rapid results, and has a high specificity as well, but it only has a sensitivity of $75 \% .{ }^{29}$ Currently, using one test for diagnosis is not recommended, because of the various sensitivities of different kits. IDSA recommends a multi-step algorithm (i.e., GDH plus toxin; GDH plus toxin, arbitrated by NAAT; or NAAT plus toxin) to correctly diagnose a CDI. ${ }^{16}$ 


\section{Methods}

Screening of abstracts to identify available studies meeting inclusion/exclusion criteria was performed by the reviewers. Inclusion criteria includes meta-analyses and systematic reviews on the association of PPIs and CDI in adult patients published from January, 2000 to May, 2020. To explore studies available on the topic, EBSCO engines such as: Academic Search Premier, PubMed with MEDLINE, and CINAHL Plus with Full Text were searched, as well as Google Scholar. Keywords and search terms used included proton pump inhibitors or PPIs and Clostridium difficile or $C$. diff. Studies describing patients using both PPIs and antibiotics concomitantly were excluded, due to the known association between antibiotic use and CDIs. The risks were categorized in minimal (OR 1.1 to 1.49), moderate (OR 1.5 to 1.9), and high (OR 2.0 or higher) based on the reported odds ratio (OR).

\section{Results}

The study reviewed published full-text meta-analyses and systematic reviews to evaluate the risk of PPI use with CDI. The search primarily yielded 1,073 studies, of whom 333 studies were reviewed, and the remaing 740 studies were unrelated to the topic of interest. Out of the reviewed studies, 8 met the inclusion criteria. The studies were conducted in U.S., Canada, Europe, and Asia. The study noted the findings based on the odds ratio or relative risk, $95 \%$ confidence interval, and $p$ values. Five studies reported moderate risk between PPI use and $\mathrm{CDI}$ incidence.

The systematic review conducted by Leonard and collegues in 2007 evaluated the effect of acid suppression on the risk of developing enteric infections such as Salmonella, Campylobacter and CDI in hospitalized adult patients. The study reviewed 19 observational studies that assessed 2,948 patients with a confirmed CDI diagnosis. Patients in this review were either on PPIs or histamine 2 receptor antagonists (H2RA). The authors found an increased risk of CDIs in patients on acid suppression therapy; patients were 1.94 times more likely to develop a CDI when on a PPI or H2RA (pooled odds ratio [OR] $1.94,95 \% \mathrm{Cl} 1.37-2.75)$. The authors further assessed the effect of PPIs and H2RAs independently. Those on PPIs are almost twice as likely to develop a CDI compared to non-users (OR $1.96,95 \% \mathrm{Cl} 1.28$ - 3.00). However, the H2RA's independent effect on CDI was found to be statistically insignificant (OR 1.40, $95 \% \mathrm{Cl} 0.85-2.29)$. Some of the studies included patients with antibiotic use without adjustments. ${ }^{30}$

In 2012, Janarthanan et al examined 23 studies; 6 cohort and 17 case-control studies done in the US, Canada, Europe and South Korea. Most cases were predominantly done in an inpatient setting with 4 out of 23 were in a community setting. Although the total duration of PPI use was not specified in most studies, all the studies include patients that were on PPI therapy for at least three months prior to having acute onset diarrhea with laboratory confirmed CDI. Finally, the analysis found that about $65 \%$ of PPI users were likely to develop CDI compared to non-users. ${ }^{31}$

Deshpande et al examined 30 observational studies in their meta-analysis; 5 cohort and 25 case control studies, which included 202,965 patients from the US, UK, Canada and South Korea with a mean age of 71 years old. Four out of the 30 studies were done in outpatient settings, while the rest were done in an inpatient setting. The analysis of the above studies found a higher risk of CDI with PPI therapy when compared to non-PPI users (OR 2.15; 95\% Cl 1.81-2.70; $\mathrm{P}<0.00001)$. The studies were adjusted for confounders and prognostic factors such as age, use of antibiotics, use of H2RAs and antimotility agents. $^{32}$

Tleyjeh et al reviewed 37 case-control and 14 cohort studies in their meta-analysis. The authors pooled odds ratios (used by 46 studies) and hazard ratios (used by 5 studies) with an assumption that both risk measures estimated the same association between PPIs and CDI based on the low CDI incidence. The adjusted pooled OR was 1.51 (95\% Cl, 1.26-1.83). Although the association was found to be statistically significant, the authors concluded that the association is not clinically significant based on the heterogeneity of the 51 studies and the number needed to harm (NNH) value of 3925 at 1 year. The authors noted that the risk of association was highest in hospitalized patients receiving antibiotics with an estimated $\mathrm{NNH}$ of 50 at 2 weeks. ${ }^{33}$

Arriola et al examined the association between hospitalacquired CDI and PPIs. Of the 186,033 cases from 23 studies (19 case-control and 4 cohort), 10,307 met their eligibility criteria from the US, Canada, UK, South Korea, Israel and China. The adult population varied from the age of 30 to 98 with a mean of 70 years old. The meta-analysis included studies primarily consisting of hospitalized patients with the exception of three studies which focused on patients in the intensive care unit. A total of 18 of the 23 studies identified confounding factors which included, but not limited to, antibiotics use, immunocompromised, the use and duration of H2RA or other PPIs, Chronic Kidney Disease, and Diabetes Mellitus. This study compared the use of patients using PPIs versus the patients not using PPIs. The relationship between PPI and CDI was broken down into cohort and case control studies. The cohort studies showed a pooled odds ratio of 1.97 (95\% Cl 1.29-2.98) representing there is a statistically significant increase risk of $\mathrm{CDI}$. The case-control analysis was shown to have an odds ratio of 1.77 (95\% Cl 1.46-2.14), which is also indicative of a statistically significant increase risk. The authors reported the pooled odds ratio for all 23 studies which was found to be 1.81 $(95 \% \mathrm{Cl} 1.52-2.14) .^{34}$

Another meta-analysis was done by Trifan et al in 2017 that included 56 studies (40 case-control and 16 cohort) and 356,683 patients. These patients were represented in both the inpatient and outpatient setting in the US, Asia, and Europe 
majority of them being single centered. The proportion of males ranged from $47 \%$ to $67 \%$ with most the population being adults older than 18 years old. All 56 studies of PPI users versus non-users expressed the results being statistically significant with an OR of 1.99, $(\mathrm{Cl}: 1.73-2.30, \mathrm{P}<0.001)$. This analysis concluded that the risk of acquiring $C$. difficile is almost two times higher in PPI users than in non-users. ${ }^{35}$

Cao et al reviewed 50 studies in their meta-analysis, which all showed a significant association between PPI use and CDI. ${ }^{35}$ These findings were especially significant in the inpatient setting with a relative risk of $1.29(1.14-1.44)$ as opposed to the relative risk in the outpatient setting 1.17 (0.74-1.59). The authors further stratified the risk of PPI use on CDI in the inpatient setting by examining CDI cases in the ICU and the medical units. Based on their results, patients on PPIs in medicine units had a greater risk of acquiring $\mathrm{CDI}$ as opposed to ICU patients with an Odds ratio of 1.26; (95\% confidence interval: $1.12-1.39) .^{36}$

Lastly, systematic review and meta-analysis conducted by Oshima et al in 2018 incorporated not only adults, but pediatrics defined as $<18$ years old to be examined. The total 67 studies in multiple countries were a combination of casecontrol (50) and cohort (16) studies or one study that consisted of both a case-control and cohort. The setting of these studies was both inpatient and outpatient. The results showed an OR of 2.34; (95\% Cl 1.94-2.82; $\mathrm{P}<0.00001)$. This is indicative of a statistically significant increase risk of C.diff with the use of PPIs as opposed to those who did not use PPIs. Furthermore, this study performed subgroup analyses to represent the effects of adults and pediatrics independently, which yielded OR of 2.30, (95\% Cl 1.89-2.80, $\mathrm{P}<0.00001)$ and $\mathrm{OR}$ of $3.00,(95 \% \mathrm{Cl} 1.44-$ $6.23, P<0.00001)$ respectively. The authors concluded that there is an increase in incidence with the use of PPI in both adults and pediatrics and should not be given to a patient at any age unless medically necessary. ${ }^{37}$

\section{Discussion}

The use of PPI and the incidence of CDI appear to be positively associated each other based on the review of meta-analyses and systematic reviews. In this evaluation, all 8 studies reported an increase in developing CDI as compared to those groups who were not prescribed PPIs. Patients in included studies did not take antibiotics, which is known as a significant confounder of the association.

The odds ratio of each study was classified into three categories: OR of 1.1 to $<1.5$ is considered minimal risk, 1.5 to 2 is moderate risk, and $>2$ is high risk. Results from metaanalyses ranged from minimal to high risk, but the majority found moderate risk associated with use and CDI incidence. An important finding was an association between PPI use with incident and recurrent $\mathrm{CDI} .{ }^{32}$ These findings also revealed risk associated with all acid suppressing drugs, PPIs and $\mathrm{H} 2$ blockers, seen in an analysis of pooled groups. ${ }^{30}$
Although the current evidence supports a positive association between $\mathrm{PPI}$ use and $\mathrm{CDI}$ incidence, PPIs remain the most effective medication in their therapeutic class, due to their minimal side effects, low tolerance, and effectiveness in prolonging gastric acid suppression (as opposed to H2RA). Therefore, clinicians may feel resigned to prescribing them due to their superior efficacy in the prophylaxis and symptomatic treatment of GERD and other related diseases. ${ }^{36}$

PPIs are currently indicated for dyspepsia and GERD. According to the dyspepsia management guidelines by the American College of Gastroenterology and the Canadian Association of Gastroenterology, PPIs are warranted for patients experiencing epigastric pain for 1 month or longer. ${ }^{38}$ A trial of PPIs is also warranted for symptomatic patients that test negative for Helicobacter pylori. Patients under 60 years of age who test $\mathrm{H}$. pylori positive and do not respond to treatment for $\mathrm{H}$. pylori, may continue to use PPIs. However, patients aged 60 years and older should have an endoscopy to rule out cancer prior to initiating a PPI. ${ }^{38}$ While for GERD, patients will present with typical symptoms of heartburn and regurgitation. And according to the guidelines, PPIs can be used empirically for GERD treatment or can be prescribed as an 8-week course to treat erosive GERD. ${ }^{38}$ For both conditions, further evaluation is needed if patients also present with alarm symptoms such as weight loss, anemia, vomiting and other serious symptoms. ${ }^{39}$

Lastly, to ensure proper usage of PPIs, pharmacists in any practice setting should follow evidence-based guidelines to develop institutional protocols guiding PPI prescribing practices. Pharmacists providing Transition of Care services in an in-patient or out-patient setting should screen and recommend stopping unnecessary use of PPIs as a way to prevent CDI. Pharmacists implementing and tracking PPI usage with Medication Use Evaluations (MUEs) can report findings to the health-system Pharmacy \& Therapeutics Committee. As medication experts, pharmacists should educate other healthcare professionals on the risks of PPI associated CDI. A health-system approach utilizing Health Information Technology can foster appropriate use and duration of PPI therapy.

\section{Acknowledgement: None}

Funding/Support: None

Conflict of interest: None 


\section{References}

1. U.S. Food and Drug Administration. Proton pump inhibitors: US Food and Drug Administrationapproved indications and dosages for use in adults [Internet] Silver Spring: U.S. Food and Drug Administration; 2014. [cited 2020 Mar 24]. Available from: http://www.fda.gov/drugs

2. Guh AY, Kutty PK. Clostridioides difficile Infection. Ann Intern Med. 2018;169(7):ITC49-64. doi:10.7326/AITC201810020.

3. Clostridium difficile - Pathogen or pest? Paediatr Child Health. 2000;5(6):349-359.

4. Luo H, Fan Q, Xiao S, Chen K. Changes in proton pump inhibitor prescribing trend over the past decade and pharmacists' effect on prescribing practice at a tertiary hospital. BMC Health Serv Res. 2018;18(1):537. doi:10.1186/s12913-018-3358-5

5. Grant K, Al-Adhami N, Tordoff J, et al. Continuation of Proton Pump Inhibitors from Hospital to Community. Pharm World Sci. 2006;28(4):189-193. doi:10.1007/s11096-006-9028-4.

6. U.S. Food and Drug Administration. Proton pump inhibitors: US Food and Drug Administrationapproved indications and dosages for use in adults. Available at: http://www.fda.gov/drugs. Accessed May 24, 2020.

7. Laine L, Shah A, Bemanian S. Intragastric $\mathrm{pH}$ with Oral vs Intravenous Bolus Plus Infusion Proton-Pump inhibitor therapy in patients with bleeding ulcers. Gastroenterology. 2008;134(7):1836-41.

8. Strand DS, Kim D, Peura DA. 25 Years of Proton Pump Inhibitors: A Comprehensive Review. Gut Liver. 2017;11(1):27-37. doi:10.5009/gnl15502.

9. Lessa FC, Mu Y, Bamberg WM, et al. Burden of Clostridium difficile Infection in the United States. Engl J Med. 2015; 372(9):825-34.

10. Centers of Disease Control and Prevention. 2017 Annual Report for the Emerging Infections Program for Clostridioides difficile Infection. Available at: https://www.cdc.gov/hai/eip/Annual-CDI-Report2017.html. Accessed April 8, 2020.

11. Mollard S, Lurienne L, Heimann SM, Bandinelli PA. Burden of Clostridium (Clostridioides) difficile infection during inpatient stays in the USA between 2012 and 2016. The Journal of hospital infection. 2019;102(2):135-140. doi: 10.1016/j.jhin.2019.01.020.

12. Rineh A, Kelso MJ, Vatansever F, Tegos GP, Hamblin MR. Clostridium difficile infection: molecular pathogenesis and novel therapeutics. Expert Rev Anti Infect Ther. 2014;12(1):131-150. doi:10.1586/14787210.2014.866515

13. Clostridium difficile - Pathogen or pest? Paediatr Child Health. 2000;5(6):349-359.
14. Kuehne S, Cartman S, Heap J, et al. The Role of Toxin $A$ and Toxin $B$ in Clostridium difficile Infection. Nature 467, 711-713 (2010). doi.org/10.1038/.

15. Hookman P, Barkin JS. Clostridium difficile Associated Infection, Diarrhea and Colitis. World J Gastroenterol. 2009;15(13):1554-1580. doi:10.3748/wjg.15.1554

16. McDonald LC, Gerding DN, Johnson S, et al. Clinical Practice Guidelines for Clostridium difficile Infection in Adults and Children: 2017 Update by the Infectious Diseases Society of America (IDSA) and Society for Healthcare Epidemiology of America (SHEA). Clin Infect Dis. 2018;66(7): 1-48. doi:10.1093/cid/cix1085

17. Hung $Y, K o W$, Chou $P$, et al. Proton-Pump Inhibitor Exposure Aggravates Clostridium difficile-Associated Colitis: Evidence from a Mouse Model. The Journal of Infectious Diseases. 2015;212(4):654663.doi:10.1093/infdis/jiv184.

18. Sorg JA, Sonenshein AL. Bile Salts and Slycine as Cogerminants for Clostridium difficile Spores. J Bacteriol. 2008;190(7):2505-2512. doi:10.1128/JB.01765-07.

19. Voth DE, Ballard JD. Clostridium difficile Toxins: Mechanism of Action and Role in Disease. Clinical Microbiology Reviews.2005;18 (2) 247-263; doi: 10.1128/CMR.18.2.247-263.2005

20. Nusrat A, Giry M, et al. Rho Protein Regulates Tight Junctions and Perijunctional Actin Organization in Polarized Epithelia. Proceedings of the National Academy of Sciences.1995;92 (23) 10629-10633; doi:10.1073/pnas.92.23.10629

21. Chen ML, Pothoulakis $C$, et al. Protein kinase $C$ Signaling Regulates ZO-1 Translocation and Increased Paracellular Flux of T84 Colonocytes Exposed to Clostridium difficile Toxin A. J. Biol. Chem.2002; 277:4247-4254.

22. Moore R, Pothoulakis C, LaMont JT, Carlson S, Madara JL. $C$. difficile Toxin A Increases Intestinal Permeability and Induces Cl-Secretion. Am J Physiol. 1990; 259:165-172

23. Pothoulakis C, Lamont JT. Microbes and microbial toxins: paradigms for microbial-mucosal interactions II. The integrated response of the intestine to Clostridium difficile toxins. Am J Physiol Gastrointest Liver Physiol. 2001; 280:178-183.

24. Gupta P, Yakubov S, Tin K, et al. Does Alkaline Colonic $\mathrm{pH}$ Predispose to Clostridium difficile Infection? Southern Medical Journal. 2016;109(2):91-96. doi:10.14423/smj.0000000000000414.

25. A. N. Edwards et al., Chemical and Stress Resistances of Clostridium difficile Spores and Vegetative Cells. Frontiers in Microbiology. 2016;7. doi:10.3389/fmicb.2016.01698. 
26. UniProt ConsortiumEuropean Bioinformatics InstituteProtein Information ResourceSIB Swiss Institute of Bioinformatics. Comparative genome and phenotypic analysis of Clostridium difficile 027 strains provide insight into the evolution of a hypervirulent bacterium. Available at:

https://www.uniprot.org/proteomes/UP000002070. Accessed April 2, 2020.

27. Daniela $W$, Shonna $M$, et al. The Impact of $\mathrm{pH}$ on Clostridioides difficile Sporulation and Physiology. Applied and Environmental Microbiology. 2020;86(4):02706-19. doi:10.1128/AEM.02706-19.

28. Tenover FC, Baron EJ, Peterson LR, Persing DH. Laboratory Diagnosis of Clostridium difficile Infection Can Molecular Amplification Methods Move Us Out of Uncertainty? J Mol Diagn. 2011;13(6):573-582. doi: 10.1016/j.jmoldx.2011; 06(1).

29. Swindells J, Brenwald N, et al. Evaluation of Diagnostic Tests for Clostridium difficile Infection. $J$ Clin Microbiol. 2010;48(2):606-8.

30. Leonard J, Marshall JK, Moayyedi P. Systematic review of the risk of enteric infection in patients taking acid suppression. Am J Gastroenterol. 2007;102(9):2047-56.

31. Janarthanan S, Ditah I, Adler DG, et al. Clostridium difficile-associated diarrhea and proton pump inhibitor-therapy: a meta-analysis. Am J Gastroenterol. 2012;107(7):1001-10. Doi: 10.1038/ajg.2012.179

32. Deshpande A, Pant C, Pasupuleti V, et al. Association Between Proton Pump Inhibitor Therapy and Clostridium difficile Infection in a Meta-Analysis. Clin Gastroenterol Hepatol. 2012;10(3):225-233.
33. Tleyjeh I, Abdulhak AB, Riaz M, et al., Association between Proton Pump Inhibitor Therapy and Clostridium difficile infection: A Contemporary Systematic Review and Meta-Analysis. PLoS One. 2012; 7(12): e50836. DOI: 10.1371/journal.pone.0050836

34. Arriola V, Tischendorf J, Musuuza J, et al. Assessing the Risk of Hospital-Acquired Clostridium Difficile Infection with Proton Pump Inhibitor Use: A MetaAnalysis. Infect Control Hosp Epidemiol. 2016;37(12):1408-1417. doi:10.1017/ice.2016.194

35. Trifan A, Stanciu C, Girleanu I, et al. Proton pump inhibitors therapy and risk of Clostridium difficile infection: Systematic review and meta-analysis. World J Gastroenterol. 2017;23(35):6500-6515. doi:10.3748/wjg. v23.i35.6500

36. Cao F, Chen CX, Wang M, et al. Updated metaanalysis of controlled observational studies: protonpump inhibitors and risk of Clostridium difficile infection. J Hosp Infect. 2018; 98:4-13.

37. Oshima $T, W u L$, Li M, et al. Magnitude and direction of the association between Clostridium difficile infection and proton pump inhibitors in adults and pediatric patients: a systematic review and metaanalysis [published correction appears in J Gastroenterol. 2020 Apr;55(4):475-480]. J Gastroenterol. 2018;53(1):84-94. doi:10.1007/s00535-017-1369-3.

38. Moayyed PM, Lacy B, Andrews C. Clinical Guideline: Management of Dyspepsia. American Journal of Gastroenterology. 2017;112(7): 988-1013.doi: 10.1038/ajg.2017.154

39. Katz PO, Gerson LB, Vela MF, et al. Guidelines for the Diagnosis and Management of Gastroesophageal Reflux Disease. American Journal of Gastroentereology. 2013:108(3):308-328. doi: 10.1038/ajg.2012.444 
Table 1: Characteristics of the Studies Included

\begin{tabular}{|c|c|c|c|c|c|c|}
\hline Source & Study design & $\begin{array}{c}\text { Number of } \\
\text { subjects }\end{array}$ & Population & Comparison & $\begin{array}{c}\text { Results (OR } \\
\text { or RR with } \\
95 \% \mathrm{Cl}, \\
\text { p-value) }\end{array}$ & Risk category \\
\hline $\begin{array}{l}\text { Leonard J, } \\
2007\end{array}$ & $\begin{array}{l}\text { Systematic } \\
\text { Review }\end{array}$ & $\begin{array}{l}12 \text { studies, } \\
2,948 \text { patients }\end{array}$ & $\begin{array}{l}\text { Inpatient } \\
\text { adults in US, } \\
\text { Canada, and UK }\end{array}$ & $\begin{array}{l}\text { PPI users vs non- } \\
\text { users }\end{array}$ & $\begin{array}{l}\text { OR } 1.96 \\
(95 \% \mathrm{Cl} 1.28 \\
-3.00) \\
\end{array}$ & $\begin{array}{l}\text { Moderate } \\
\text { risk }\end{array}$ \\
\hline $\begin{array}{l}\text { Deshpande A, } \\
2012\end{array}$ & Meta-Analysis & $\begin{array}{l}30 \text { studies, } \\
202,965 \\
\text { patients }\end{array}$ & $\begin{array}{l}\text { Inpatient, } \\
\text { outpatient and } \\
\text { nursing home } \\
\text { in the UK, } \\
\text { Canada, US } \\
\text { and South } \\
\text { Korea. }\end{array}$ & $\begin{array}{l}\text { PPI users vs Non- } \\
\text { users. }\end{array}$ & $\begin{array}{l}\text { OR } 2.15( \\
95 \% \mathrm{Cl} 1.81- \\
2.55 \\
\mathrm{P}<0.001)\end{array}$ & High risk \\
\hline $\begin{array}{l}\text { Janarthanan S, } \\
2012\end{array}$ & Meta-Analysis & $\begin{array}{l}23 \text { studies, } \\
288,620 \\
\text { patients }\end{array}$ & & $\begin{array}{l}\text { PPI users vs Non- } \\
\text { users }\end{array}$ & $\begin{array}{l}\text { RR 1.654( } \\
95 \% \mathrm{Cl} \\
1.415-1.97 \\
\mathrm{P}<0.001)\end{array}$ & $\begin{array}{l}\text { Moderate } \\
\text { risk }\end{array}$ \\
\hline Tleyjeh I, 2012 & $\begin{array}{l}\text { Systematic } \\
\text { Review \& } \\
\text { Meta-Analysis }\end{array}$ & $\begin{array}{l}47 \text { studies } \\
\text { (Number of } \\
\text { patients in } \\
\text { each study } \\
\text { was not } \\
\text { reported) }\end{array}$ & $\begin{array}{l}\text { Inpatient and } \\
\text { outpatient } \\
\text { adults in Asia, } \\
\text { US, Canada } \\
\text { and Europe }\end{array}$ & $\begin{array}{l}\text { PPI users vs non- } \\
\text { users }\end{array}$ & $\begin{array}{l}\text { Adjusted } \\
\text { pooled OR } \\
\text { of } 1.51 \text { (95\% } \\
\mathrm{Cl}, 1.26- \\
1.83)\end{array}$ & $\begin{array}{l}\text { Moderate } \\
\text { risk }\end{array}$ \\
\hline Arriola V, 2016 & Meta-Analysis & $\begin{array}{l}23 \text { studies, } \\
10,307 \\
\text { patients }\end{array}$ & $\begin{array}{l}\text { Inpatient or } \\
\text { ICU adults in } \\
\text { US, Canada, } \\
\text { South Korea } \\
\text { and UK. }\end{array}$ & $\begin{array}{l}\text { PPI users vs Non- } \\
\text { users. }\end{array}$ & $\begin{array}{l}\text { Pooled OR } \\
1.81(95 \% \mathrm{Cl} \\
1.52-2.14)\end{array}$ & $\begin{array}{l}\text { Moderate } \\
\text { risk }\end{array}$ \\
\hline Trifan A, 2017 & Meta-Analysis & $\begin{array}{l}56 \text { studies, } \\
356,683 \\
\text { patients }\end{array}$ & $\begin{array}{l}\text { Inpatient and } \\
\text { Outpatient } \\
\text { adults in US, } \\
\text { Asia and } \\
\text { Europe }\end{array}$ & $\begin{array}{l}\text { PPI users vs non- } \\
\text { PPI users }\end{array}$ & $\begin{array}{l}\text { OR } 1.99( \\
95 \% \mathrm{Cl} 1.73- \\
2.30 ; \mathrm{P}< \\
0.001)\end{array}$ & $\begin{array}{l}\text { Moderate } \\
\text { risk }\end{array}$ \\
\hline Cao F, 2018 & Meta-Analysis & $\begin{array}{l}50 \text { studies, } \\
342,532 \\
\text { patients }\end{array}$ & $\begin{array}{l}\text { Inpatient, } \\
\text { outpatient and } \\
\text { ICU patients }\end{array}$ & $\begin{array}{l}\text { PPI users vs non- } \\
\text { PPI users }\end{array}$ & $\begin{array}{l}\text { OR } 1.26( \\
95 \% \mathrm{Cl} 1.12- \\
1.39 ; \mathrm{P}< \\
0.001)\end{array}$ & Minimal risk \\
\hline Oshima T, 2018 & $\begin{array}{l}\text { Systematic } \\
\text { review and } \\
\text { Meta-analysis }\end{array}$ & 67 studies & $\begin{array}{l}\text { Inpatient and } \\
\text { outpatient } \\
\text { adults and } \\
\text { pediatrics in } \\
\text { the UK, } \\
\text { Canada, US, } \\
\text { Netherlands, } \\
\text { South Korea, } \\
\text { Italy, Iceland, } \\
\text { Romania, } \\
\text { Germany, } \\
\text { Japan, Spain, } \\
\text { China, and } \\
\text { Belgium }\end{array}$ & $\begin{array}{l}\text { PPI vs non- PPI } \\
\text { users }\end{array}$ & $\begin{array}{l}\text { OR } 2.34( \\
95 \% \mathrm{Cl} \\
1.94-2.82 \\
\mathrm{P}<0.001)\end{array}$ & High Risk \\
\hline
\end{tabular}

